\title{
Antioxidative Activity of Carotenoids in Mideodeok Styela clava
}

\author{
Loda M. Nacional ${ }^{1}$, Seok-Joong Kang ${ }^{2}$ and Byeong-Dae Choi ${ }^{3 *}$ \\ ${ }^{1}$ College of Aquatic Sciences and Applied Technology, Mariano Marcos State University, Currimao 2903, Ilocos Norte, Philippines \\ ${ }^{2}$ Deptartment of Marine Life Science/Institute of Marine Industry, Gyeongsang National University, Tongyeong 650-160, Korea \\ ${ }^{3}$ Department of Seafood Science and Technology/Institute of Marine Industry, Gyeongsang National University, Tongyeong 650-160, \\ Korea
}

\begin{abstract}
s
Carotenoids were found in high levels in both muscle and tunic samples, with the highest and lowest values observed in March and January, respectively. The average values in muscle (GM) and tunic (GT) harvested in Geoje were $49.1 \mathrm{mg} / 100 \mathrm{~g}$ and $56.7 \mathrm{mg} / 100 \mathrm{~g}$, respectively, whereas those in muscle (TM) and tunic (TT) harvested in Tongyeong were $42.0 \mathrm{mg} / 100 \mathrm{~g}$ and $50.2 \mathrm{mg} / 100 \mathrm{~g}$, respectively. The total phenol contents of the tunic were not significantly different $(P<0.05)$ between sampling area and month. We investigated the antioxidative activities of the carotenoids against linoleic acid peroxidation [1,1-diphenyl-2-picrylhydrazyl (DPPH)] and hydroxyl radicals as well as their reducing power. The DPPH radical scavenging activity was 7.6-13.5\% in GM, which is relatively weak, whereas it was $21.1-29.9 \%$ in GT, 9.6-12.4\% in TM and $19.3-24.1 \%$ in TT. In comparison to $\alpha$-tocopherol, the carotenoids were found to have strong inhibitory effects against linoleic acid peroxidation, and exhibited strong hydroxyl radical scavenging activities and reducing power at $120 \mu \mathrm{g} / \mathrm{mL}$ of each sample.
\end{abstract}

Key words: Mideodoek, Styela clava, Carotenoids, Antioxidant activity, Free radical

\section{Introduction}

Carotenoids belong to the tetraterpenes family and are found in plants, algae, photosynthetic bacteria and marine animals. The distribution of carotenoids in marine animal sources is primarily the result of specific dietary habits, absorption, and metabolic transformation (Hosokawa et al., 2009). A high level of carotenoids was isolated from the tunicate Halocynthia roretzi, with alloxanthin, halocynthiaxanthyin, and astaxanthin as the major components (Nishibori, 1958). Two novel carotenoids, amarouciaxanthin A and B, were isolated from the tunicate Amaroucium pliciferum (Matsuno et al., 1985). Rebachuk et al. (1985) showed that astaxanthin and diatoxanthin are the main carotenoids in the tunicate Halocynthia aurantium. The biochemical contents of marine organisms are directly affected by seasonal changes (Orban et al., 2002) and geographical location (Karakoltsidis et al., 1995). Both season and geographical location have profound effects on the temperature, salinity levels and food availability of the marine environment. Studies on the relative sensitivity of different developmental stages of Styela plicata (Lesueur) to various temperatures and salinities showed that both factors significantly affect the embryo and post-larval development of the species (Thiyagarajan and Qian, 2003). Additionally, H. aurantium exhibited a very limited capacity to survive an acute temperature elevation, for example, during thermal currents, due to a lack of effective homeoviscous mechanisms (Sanina and Kostetsky, 2002). Several studies (e.g., Tsuchiya and Suzuki, 1960; Yen et al., 2000) examining the composition of carotenoids present in marine organisms have reported that marine tunicates are a rich source of carotenoids.

Carotenoids serve a protective role by effectively dissipating excess energy, preventing the formation of reactive oxygen species (ROS), and by deactivating singlet oxygen molecules
Open Access http://dx.doi.org/10.5657/FAS.2011.0243

This is an Open Access article distributed under the terms of the Creative Commons Attribution Non-Commercial License (http://creativecommons. org/licenses/by-nc/3.0/) which permits unrestricted non-commercial use, distribution, and reproduction in any medium, provided the original work is properly cited. pISSN: 2234-1749 eISSN: 2234-1757
Received 13 August 2011; Revised 29 September 2011; Accepted 7 November 2011

*Corresponding Author

E-mail: bdchoi@gnu.ac.kr 
generated during the photosynthetic process (Chew and Park, 2004; Jackson et al., 2008). In addition, dietary carotenoids react with a wide range of free radicals such as $\mathrm{CCl}_{3} \mathrm{O}_{2}, \mathrm{RSO}_{2}$, $\mathrm{NO}_{2} \cdot$ and various arylperoxy radicals via electron transfer, producing the radical cations of the carotenoids. DPPH radicals and the 2, 2'-azinobis-3-ethylbenzotiazoline-6-sulphonic acid (ABTS) radical scavenging assay are popular indirect methods of determining the antioxidative capacity of compounds. The DPPH radical scavenging activities of fucoxanthin and fucoxanthinol were higher than of halocynthiaxanthin, with concentrations $(\mu \mathrm{M})$ required for $50 \%$ scavenging $\left(\mathrm{EC}_{50}\right)$ of 164.6, 153.8 and 826.4, respectively. Additionally, ABTS radical scavenging activity of fucoxanthinol $\left(\mathrm{EC}_{50}-2.49 \mu \mathrm{M}\right)$ was stronger than that of fucoxanthin $\left(\mathrm{EC}_{50}-8.94 \mu \mathrm{M}\right)$. Furthermore, the hydroxyl radical scavenging activity, as measured using the chemiluminescence technique, showed that the scavenging activity by fucoxanthin was 7.9 times higher than that of fucoxanthinol, 16.3 times higher than that of halocynthiaxanthin and 13.5 times higher than that of $\alpha$-tocopherol (Shon et al., 2003).

The objectives of this study were to evaluate and compare the effect of antioxidant properties of mideodeok muscle and tunic harvested from two different areas in the southern coast of Korea. Specifically, we aimed to provide baseline information on the antioxidant capacity of mideodeok for both consumers and researchers working on ascidians, which could provide insight into more extensive use of this marine organism, particularly as food material.

\section{Materials and Methods}

\section{Materials}

Samples of Styela clava were collected from two different culture sites on the south coast of Korea (Geoje and Tongyeong) during the first week of January, March, and May 2006. Upon arrival at the laboratory, the tunics were separated from the muscle and frozen at $-40^{\circ} \mathrm{C}$ until further analysis. The solvents for extraction were obtained from Duksan Pure Chemicals Co. (Ansan, Gyeonggi, Korea). The environmental conditions such as salinity, temperature and chlorophyll levels of the culture ground were obtained from National Fisheries Research and Development Institute (2008).

\section{Extraction of carotenoids}

Carotenoids were extracted from mideodeok muscle and tunic with acetone at room temperature. After concentration under reduced pressure, the carotenoids were transferred to diethyl ether by the addition of deionized water. The resultant carotenoids were quantified using a UV Spectrophotometer (UV-1700; Shimadzu Co., Kyoto, Japan). The absorbency detection wavelength was set at $460 \mathrm{~nm}$ and the analyses were conducted in triplicate (McBeth, 1972). The total carotenoids content was calculated using the following equation: total carotenoids $(\mathrm{mg} / \mathrm{kg})=[$ O.D. $(\lambda \max ) \times$ Vol. $\times 1,000] /\left[\mathrm{E}^{1 \%}{ }_{\mathrm{lcm}}\right.$ $(2,400) \times$ weight of sample $(\mathrm{kg})]$

\section{Total phenolic content}

Total phenolic content (TPC) was determined according to the Folin-Ciocalteau method (Slinkard and Singleton, 1977) with slight modifications. Briefly, $100 \mu \mathrm{L}$ of carotinoid extract $(0.12 \%, \mathrm{w} / \mathrm{v}$ in ethanol) was mixed with $1.4 \mathrm{~mL}$ deionized water and $100 \mu \mathrm{L}$ Folin-Ciocalteu reagent (Sigma-Aldrich Co., St. Louis, MO, USA). The solution was vortexed for $30 \mathrm{~s}$. Sodium carbonate solution $(20 \%, \mathrm{w} / \mathrm{v})$ was added to the mixture and vortexed for another $30 \mathrm{~s}$. The mixture was allowed to stand at room temperature for $2 \mathrm{~h}$, after which the absorbance was measured at $765 \mathrm{~nm}$ against a blank sample. A standard calibration curve was made using different concentrations of gallic acid (Sigma-Aldrich Co.). The concentration of TPC in the sample was expressed as mg gallic acid equivalent (GAE) of extract.

\section{Linoleic acid peroxidation}

The antioxidant activity of the carotenoids was measured by linoleic acid peroxidation and was quantified using the ferric thiocyanate method (FTC) developed by Osawa and Namiki (1981). A $4 \mathrm{~mL}$ aliquot of sample $(0.12 \%, \mathrm{w} / \mathrm{v}$ in ethanol) was mixed with $4 \mathrm{~mL}$ linoleic acid $(2.5 \%, \mathrm{v} / \mathrm{v})$ in $99.5 \%$ ethanol, $8 \mathrm{~mL}$ phosphate buffer $(\mathrm{pH} 7.0,0.05 \mathrm{M})$ and $3.9 \mathrm{~mL}$ deionized water. The mixture was kept in a screwed-cap vial and incubated at $40^{\circ} \mathrm{C}$ under dark conditions until the day after the absorbance of the control reached a maximum. $\alpha$-Tocopherol and butylated hydroxyanisole (BHA) were prepared under the same conditions as the positive standards. The control was prepared in the same way but without the test compound. FTC analysis was carried out at 2 day intervals.

\section{DPPH radical scavenging activity}

The free radical scavenging activities of the carotenoids were measured using the DPPH method modified after Oyaizu (1986). A $0.5 \mathrm{~mL}$ aliquot of the $0.5 \mathrm{mM}$ DPPH-ethanol solution was added to $1 \mathrm{mg} / \mathrm{mL}$ of carotenoids $(0.12 \%$, w/v in ethanol). Next, $1 \mathrm{~mL}$ of ethanol was added to the mixture and the volume was adjusted to $2.5 \mathrm{~mL}$ with $0.1 \mathrm{M}$ sodium acetate buffer (pH 5.5). $\alpha$-Tocopherol and BHA were prepared under the same conditions as the positive standards. The mixture was shaken vigorously and left at room temperature for 30 min. The absorbance was measured at $517 \mathrm{~nm}$.

\section{Hydroxyl radical scavenging activity}

The hydroxyl radical scavenging activity of the carotenoids 
was evaluated using the 2-deoxyribose oxidation method (Chung et al., 1977) with slight modifications. Specifically, $0.2 \mathrm{~mL}$ of $10 \mathrm{mM}$ 2-deoxyribose, $0.2 \mathrm{~mL}$ of $10 \mathrm{mM} \mathrm{Fe}^{2+}$ / EDTA and $0.2 \mathrm{~mL}$ of $10 \mathrm{mM} \mathrm{H}_{2} \mathrm{O}_{2}$ were added to $10,30,50$, and $100 \mu \mathrm{L}$ of carotenoids $(0.12 \%, \mathrm{w} / \mathrm{v}$ in ethanol). The final volume, adjusted to $2 \mathrm{~mL}$ with $100 \mathrm{mM}$ phosphate buffer solution ( $\mathrm{pH} 7.4)$ and the reaction mixture, was incubated at $37^{\circ} \mathrm{C}$ for $4 \mathrm{~h}$. After incubation, $1 \mathrm{~mL}$ of each of $2.8 \%$ trichloroacetic and $1 \%$ thiobarbituric acid in $50 \mathrm{mM} \mathrm{NaOH}$ were added and the mixture was heated at $100^{\circ} \mathrm{C}$ for $10 \mathrm{~min}$, cooled in an ice bath, and the absorbance was measured at $532 \mathrm{~nm}$. The hydroxyl radical scavenging activity was calculated using the following equation:

hydroxyl radical scavenging activity $(\%)=[1-($ Sample Abs/ Control Abs)] $\times 100$

\section{Reducing power}

The reducing powers of the carotenoids were determined using the method described by Oyaizu (1986). Briefly, a sample solution was mixed with $0.5 \mathrm{~mL}$ of $0.2 \mathrm{M}$ phosphate buffer (pH 6.6) and $0.5 \mathrm{~mL}$ of potassium ferricyanide (III) $(1 \%, \mathrm{w} / \mathrm{v})$ followed by a $50^{\circ} \mathrm{C}$ incubation for $20 \mathrm{~min}$. Next, $0.5 \mathrm{~mL}$ TCA $(10 \%, \mathrm{w} / \mathrm{v})$ was added to the mixture before centrifuging at $1,036 \mathrm{~g}$ for $10 \mathrm{~min}$. A $0.5 \mathrm{~mL}$ aliquot of the upper layer of the solution was then mixed with $0.5 \mathrm{~mL}$ distilled water and 0.1 $\mathrm{mL} \mathrm{FeCl}_{3}(0.1 \%$, w/v), after which the absorbance was measured at $700 \mathrm{~nm}$. A higher absorbance was taken to indicate a greater reducing power.

\section{Statistical analysis}

Data were evaluated for statistical significance using the JMP Statistical Discovery Software ${ }^{\mathrm{TM}}$ version 5 (SAS Institute Inc., Cary, NC, USA). Values were expressed as the mean $\pm \mathrm{SD}$. The mean values were compared using a one-way analysis of variance (ANOVA) followed by Tukey's or Duncan's test. A $P$-value of less than 0.05 was considered significant.

\section{Results and Discussion}

\section{Carotenoid content}

The total carotenoid contents of the $S$. clava muscle and tunic from both sampling sites exhibited seasonal changes (Fig. 1). The carotenoid concentrations from all samples were higher in March than in January and May. The average carotenoid contents in Geoje muscle (GM), Geoje tunic (GT), Tongyeong muscle (TM), and Tongyeong tunic (TT) were $49.1 \mathrm{mg} / \mathrm{kg}$, $51.4 \mathrm{mg} / \mathrm{kg}, 42.0 \mathrm{mg} / \mathrm{kg}$ and $50.2 \mathrm{mg} / \mathrm{kg}$, respectively. These results are similar to those of carotenoid levels in the tunic of H. roretzi (Choi et al., 1994). Carotenoids are important

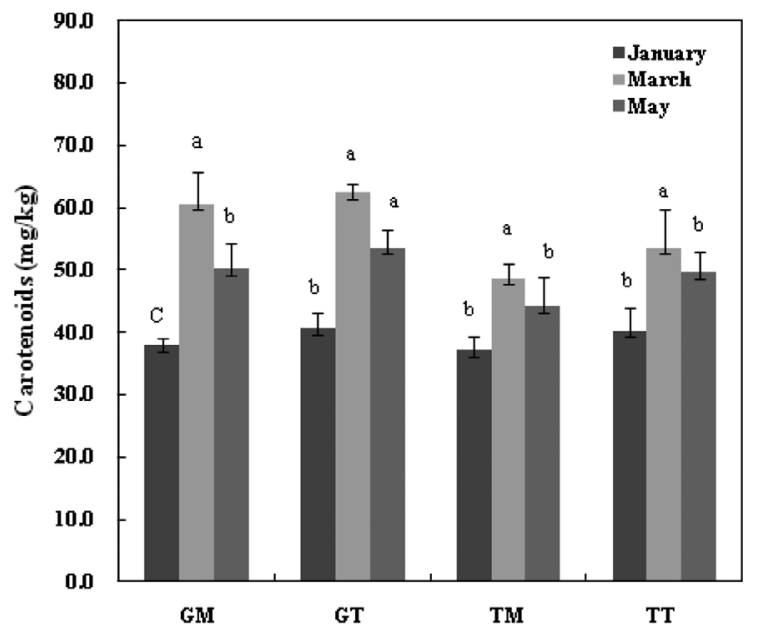

Fig. 1. Total carotenoid contents of mideodeok muscle and tunic. Values are mean with standard error of triplicates. Values not sharing the same letter are significantly different from one another $(P<0.05)$ by Duncan's multiple range test. GM, Geoje muscle; GT, Geoje tunic; TM, Tongyeong muscle; TT, Tongyeong tunic.

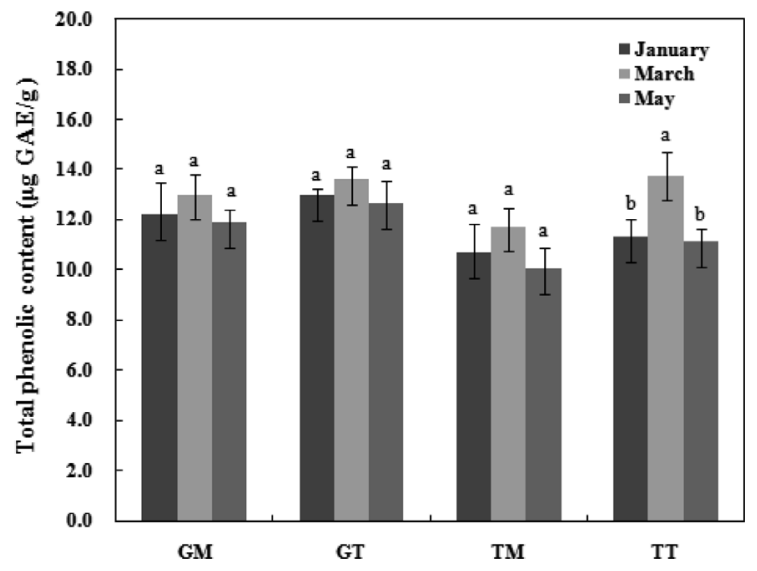

Fig. 2. Total phenolic contents of mideodeok tunic and muscle carotenoids. Values are mean with standard error of triplicates. Values not sharing the same letter are significantly different from one another $(P<$ 0.05 ) by Duncan's multiple range test. GM, Geoje muscle; GT, Geoje tunic; TM, Tongyeong muscle; TT, Tongyeong tunic.

dietary antioxidants, given their ability to counteract oxidative damage to biomolecules and protect against chronic diseases such as cancer, cardio-vascular diseases and visual degeneration in humans (Kelly et al., 1993). They also act as precursors for vitamin A by means of $\beta$-carotene. Thus, mideodeok may be a good alternative food for humans to provide the carotenoids necessary for maintaining health.

\section{Total phenolic content}

The TPC of mideodeok muscle and tunic carotenoids are shown in Fig. 2. The data are expressed as $\mu \mathrm{g}$ GAE/g carotenoids. The Geoje sample exhibited higher phenolic levels 


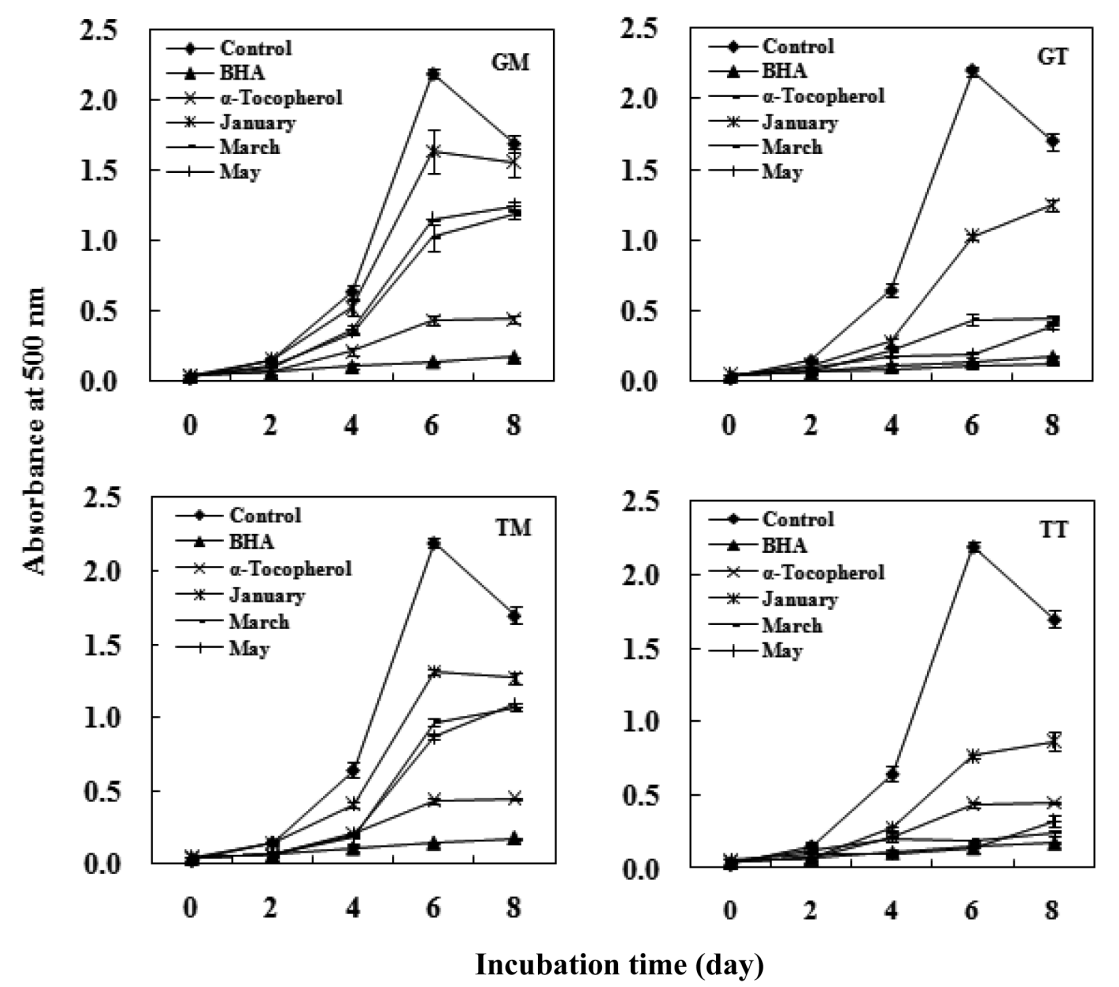

Fig. 3. Antioxidative activities of the carotenoid extracts obtained from mideodeok muscle and tunic. a-Tocopherol (a-Toc) and butylated hydroxyanisole $(\mathrm{BHA})$ were used as positive controls. Values are mean with standard error of triplicates. Values not sharing the same letter are significantly different from one another $(P<0.05)$ by Duncan's multiple range test. GM, Geoje muscle; GT, Geoje tunic; TM, Tongyeong muscle; TT, Tongyeong tunic.

than the Tongyeong sample. Furthermore, the TPC in the muscle was lower than that of the tunic extract. However, no significant differences were detected among samples, with the exception of TT. The TPC levels in GM, GT, TM, and TT ranged from 11.9-13.0 GAE $\mu \mathrm{g} / \mathrm{g}, 12.6-13.6 \mathrm{GAE} \mu \mathrm{g} / \mathrm{g}, 10.0-$ 11.7 GAE $\mu \mathrm{g} / \mathrm{g}$, and 11.1-13.8 GAE $\mu \mathrm{g} / \mathrm{g}$, respectively. Lee et al. (2010) extracted active compounds from $S$. clava using $70 \%$ ethanol and water and reported that the content of active compounds was dependent on the types of solvents used and seasonal variations. TPCs are effective hydrogen donors, making them good antioxidants (Rice-Evans et al., 1995). They are considered secondary metabolites, which belong to a large and heterogeneous group of biologically active nonnutrients that serve as active defense factors against various types of stresses caused by pathogens or adverse environmental conditions. Data describing the formation of TPC in marine organisms are scarce, but it is postulated that some environmental stresses such as low temperatures brought by the winter season may trigger the formation of this compound (Duval et al., 2000). It should be noted that mideodeok sampling was conducted during the first weeks of January, March and May. Therefore, it is possible that the low temperatures registered in February $\left(5.0^{\circ} \mathrm{C}\right.$ and $5.3^{\circ} \mathrm{C}$ in Tongyeong and Geoje, respectively), similar to those reported by Nacional et al. (2006), may have influenced the relatively high TPC levels observed in February.

\section{Linoleic acid peroxidation}

A considerable number of studies have provided in vitro evidence that the interactions of carotenoids, particularly $\beta$-carotene, with free radicals (Krinsky, 1993) produce chainbreaking antioxidants that scavenge and quench singlet oxygen. Here, antioxidative activity on the peroxidation of linoleic acid was investigated to evaluate the in vitro effects of carotenoids from mideodeok tunic and muscle samples (Fig. 3 ). The peroxide that formed during the initial stages of lipid oxidation was quantified by FTC, and the absorbance values were 1.19 in Mar, 1.25 in May, and 1.56 in the Jan GM samples, as opposed to 0.12 in Mar, 0.40 in May, and 1.25 in Jan in the GT samples after 8 days of incubation. Additionally, the TT sample exhibited higher antioxidant properties of 0.24 , 0.32 , and 0.87 , relative to TM, which showed levels of 1.06 , 1.09 , and 1.27 in Mar, May, and Jan, respectively. Tunic carotenoids extracted in Mar and May exhibited very active protective effects against linoleic acid peroxidation, even exceeding the activity of $\alpha$-tocopherol. In addition, GT and TT samples collected in March as well as TT sampled in May exhibited 
the strongest antioxidant activities, which were statistically similar to the activities of the BHA standards $(P<0.05)$. Shim et al. (2009) reported synergetic antioxidant effects of lycopene and other antioxidants on methyl linoleate autooxidation. Synergistic antioxidant effects were also observed when lycopene was used in combination with vitamin $C$, vitamin $\mathrm{E}$ and $\beta$-carotene. The tunic extract contained a mixture of carotenoids, which may have been responsible for the strong antioxidative effects.

\section{DPPH radical scavenging activity}

DPPH is a free radical compound and has been widely used to test the free radical scavenging abilities of various samples (Roginsky and Lissi, 2005). The result of the DPPH radical scavenging activity analyses are presented in Fig. 4 . The final concentrations of $\alpha$-tocopherol and BHA used were $0.1 \mathrm{mg} /$ $\mathrm{mL}$ while those of the mideodeok carotenoids were $1.0 \mathrm{mg} /$ $\mathrm{mL}$. The activities of the carotenoids were very low compared to the standards. The GT March sample showed the highest activity among extracts, with a capability of scavenging $29.9 \%$ of the $5 \mathrm{mM}$ DPPH radical for $30 \mathrm{~min}$. The muscle samples showed low activity at 7.6-13.5\% in the GM and 9.6-12.4\% in the TM. However, the standards showed greater than $75 \%$ of the DPPH radical scavenging effects at low concentrations. A positive correlation was observed between phenolic content (Fig. 2) and DPPH radical scavenging activity. Previous studies have suggested that the DPPH radical scavenging capacities of extracts are largely affected by the presence and position of the phenolic hydroxyl group. The anti-radical activity of the phenolic compound is, in turn, dependent on its molecular structure, i.e., the availability of phenolic hydrogens as well as the potential for stabilization of the resulting phenoxyl radicals formed by hydrogen donation (Procházková et al., 2011). For example, Lee et al. (2010) showed that the DPPH radical scavenging activity for the flesh part of $S$. clava was higher than that of tunic part, and water extracted from the flesh harvested in April showed the highest value (53.0\% at 10 $\mathrm{mg} / \mathrm{mL}$ ). These results indicated that the antioxidant activities of this species were variable depending on harvesting time, body part and extraction solvents.

\section{Hydroxyl radical scavenging activity}

Among reactive oxygen species, hydroxyl radicals are the most reactive and often induce severe oxidative damage to important biomolecules such as proteins, DNA, PUFA and nucleic acids, causing aging, cancer and other several diseases (Aruoma, 1998). Fig. 5 shows the hydroxyl radical scavenging activities and positive standards values of the carotenoids isolated herein. These values were compared with those of $\alpha$-tocopherol and BHA to assess the antioxidant capacities of the carotenoids at concentrations of 12 to $120 \mu \mathrm{g} / \mathrm{mL}$. Samples harvested in March exhibited the strongest radical scavenging

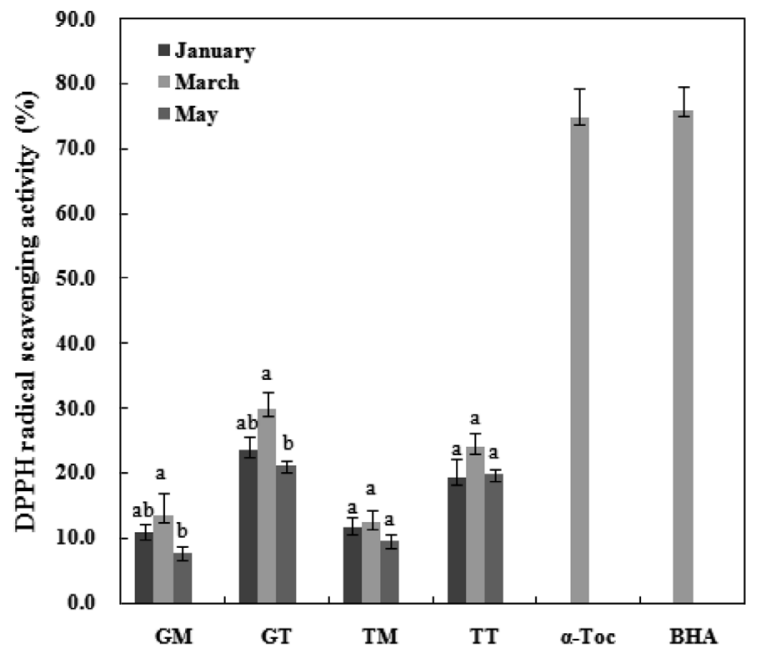

Fig. 4. DPPH radical scavenging activity of the carotenoid extracts obtained from mideodeok muscle and tunic. The concentration of a-tocopherol (a-Toc) and butylated hydroxyanisole (BHA) were $0.1 \mathrm{mg} /$ $\mathrm{mL}$. Mideodeok carotenoid concentration was $1 \mathrm{mg} / \mathrm{mL}$; $\mathrm{a}$-Tocopherol and $\mathrm{BHA}$ were used as positive controls. Values are mean with standard error of triplicates. Values not sharing the same letter are significantly different from one another $(P<0.05)$ by Duncan's multiple range test. $\mathrm{GM}$, Geoje muscle; GT, Geoje tunic; TM, Tongyeong muscle; TT, Tongyeong tunic.

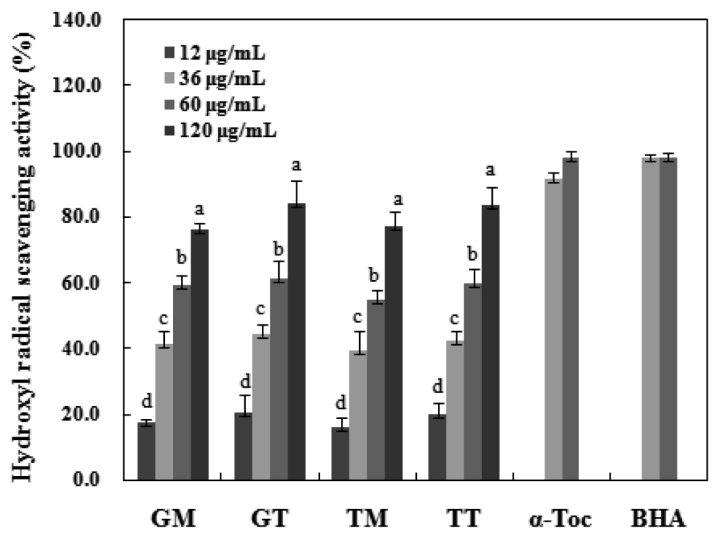

Fig. 5. Hydroxyl radical scavenging activity of the carotenoid extracts obtained from mideodeok muscle and tunic. a-Tocopherol (a-Toc) and butylated hydroxyanisole (BHA) were used as positive controls. Values are mean with standard error of triplicates. Values not sharing the same letter are significantly different from one another $(P<0.05)$ by Duncan's multiple range test. GM, Geoje muscle; GT, Geoje tunic; TM, Tongyeong muscle; TT, Tongyeong tunic.

activities. GT and TT showed maximum scavenging values of $84.4 \%$ and $83.9 \%$, respectively, at a concentration of 120 $\mu \mathrm{g} / \mathrm{mL}$. Similarly, the GM and TM carotenoids also increased in a dose-dependent manner. Conversely, the positive controls ( $\alpha$-tocopherol and BHA) did not show dose dependency and exhibited hydroxyl radical scavenging activities of approximately $98.0 \%$ and $98.3 \%$, respectively. Some seaweed extracts show weak hydroxyl radical scavenging activities of 


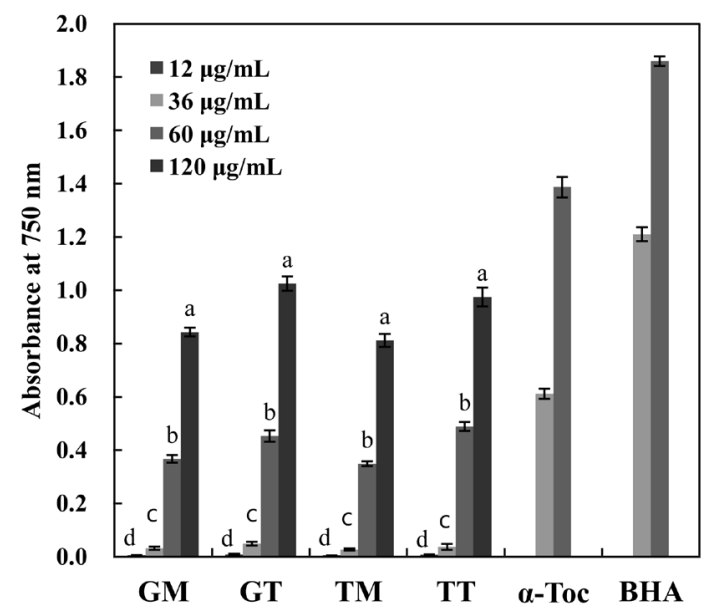

Fig. 6. Reducing power of the carotenoid extracts obtained from mideodeok muscle and tunic. a-Tocopherol (a-Toc) and butylated hydroxyanisole (BHA) were used as positive controls. Values are mean with standard error of triplicates. Values not sharing the same letter are significantly different from one another $(P<0.05)$ by Duncan's multiple range test. GM, Geoje muscle; GT, Geoje tunic; TM, Tongyeong muscle; TT, Tongyeong tunic.

approximately $40 \%$ at $\mathrm{mg}$ levels (Meir, 1995; Siriwardhana et al., 2003). However, the $90 \% \mathrm{MeOH}$ fraction evaluated in a study of Polysiphonia morrowii suggested very high scavenging activity at the $\mu \mathrm{g}$ level (Je et al., 2009). The hydroxyl radical, which is generated through the Fenton reaction in this system, was scavenged by carotenoids isolated from both tunic and muscle. These results suggest that the mideodeok carotenoids, particularly those from the tunic extracts, exhibit potent antioxidant activity and may be useful as supplements in human food or in the fish feed industry.

\section{Reducing power}

The concentration dependency of antioxidant activity was investigated as a function of reducing power (Fig. 6), as this gives a general view of reductones present in the sample. The reducing power increased with increasing concentration in all samples. Ganesan et al. (2008) reported that the reducing power of $\mathrm{MeOH}$ extracts from some red seaweeds were low at the mg level, as indicated by an optical density (OD) of $<0.2$. However, in the present study, the carotenoids of $S$. clava were found to have strong reducing power, with an OD of 1.025 when a concentration of $120 \mu \mathrm{g} / \mathrm{mL}$ was evaluated. Je et al. (2009), who examined $\mathrm{MeOH}$ extracts of a red seaweed, $P$. morrowii, also reported this trend. This property is associated with the presence of reductones, which are thought to terminate the free radical chain reaction (Duh, 1998).

In summary, both tunic and muscle yielded high levels of carotenoids, with values that are comparatively higher than those seen in other seafood species. The average values in the GM, GT, TM and TT samples were $49.1 \mathrm{mg} / 100 \mathrm{~g}, 56.7$ $\mathrm{mg} / 100 \mathrm{~g}, 42.0 \mathrm{mg} / 100 \mathrm{~g}$ and $50.2 \mathrm{mg} / 100 \mathrm{~g}$, respectively. The crude carotenoids of both tunic and muscle samples were tested for antioxidant activities, and both exhibited weak DPPH scavenging activities. However, these samples exhibited a strong inhibitory effect against linoleic acid peroxidation, with the degrees of inhibition being comparable to those of the $\alpha$-tocopherol and BHA standards. Furthermore, all samples showed strong hydroxyl radical scavenging activities and reducing power, particularly the GT and TT samples collected in March, which exhibited values similar to those of $\alpha$-tocopherol.

\section{References}

Aruoma OI. 1998. Free radicals, oxidative stress, and antioxidants in human health and disease. J Am Oil Chem Soc 75, 199-212.

Chew BP and Park JS. 2004. Carotenoid action on the immune response. J Nutr 134, 257S-261S.

Choi BD, Kang SJ, Choi YJ, Youm MG and Lee KH. 1994. Utilization of ascidian (Halocynthia roretzi) tunic. 3. Carotenoid composition of ascidian tunic. Bull Korean Fish Soc 27, 344-350.

Chung SK, Osawa T and Kawakishi S. 1977. Hydroxyl radical scavenging effects of spices and scavengers from brown mustard (Brassica nigra). Biosci Biotechnol Biochem 61, 118-123.

Duh PD. 1998. Antioxidant activity of burdock (Arctium lappa Linné): its scavenging effect on free-radical and active oxygen. J Am Oil Chem Soc 75, 455-461.

Duval B, Shetty K and Thomas WH. 2000. Phenolic compounds and antioxidant properties in the snow alga Chlamydomonas nivalis after exposure to UV light. J Appl Phycol 11, 559-566.

Ganesan P, Kumar CS and Bhaskar N. 2008. Antioxidant properties of methanol extract and its solvent fractions obtained from selected Indian red seaweeds. Bioresour Technol 99, 2717-2723.

Hosokawa M, Okada T, Mikami N, Konishi I and Miyashita K. 2009. Bio-functions of marine carotenoids. Food Sci Biotechnol 18, 1-11.

Jackson H, Braun CL and Ernst H. 2008. The chemistry of novel xanthophyll carotenoids. Am J Cardiol 101, 50D-57D.

Je JY, Ahn CB, Oh MJ and Kang SY. 2009. Antioxidant activity of a red seaweed Polysiphonia morrowii extract. Food Sci Biotechnol 18, 124-129.

Karakoltsidis PA, Zotos A and Constantinides SM. 1995. Composition of the commercially important Mediterranean finfish, crustaceans, and molluscs. J Food Compost Anal 8, 258-273.

Kelly KL, Cooper EL and Raftos DA. 1993. A humoral opsonin from the solitary urochordate Styela clava. Dev Comp Immunol 17, 2939.

Krinsky NI. 1993. Actions of carotenoids in biological systems. Annu Rev Nutri 13, 561-587.

Lee DW, You DH, Yang EK, Jang IC, Bae MS, Jeon YJ, Kim SJ and Lee SC. 2010. Antioxidant and ACE inhibitory activities of Styela clava according to harvesting time. J Korean Soc Food Sci Nutr 39, 331-336.

Matsuno T, Ookubo M and Komori T. 1985. Carotenoids of tunicates. 
III. The structural elucidation of two new marine carotenoids, amarouciaxanthin A and B. J Nat Prod 48, 606-613.

McBeth JW. 1972. Carotenoids from nudibranchs. Comp Biochem Physiol B Biochem Mol Biol 41, 55-68.

Meir S, Kanner J, Akiri B and Philosoph-Hadas S. 1995. Determination and involvement of aqueous reducing compounds in oxidative defense systems of various senescing leaves. J Agric Food Chem 43, 1813-1819.

Nacional LM, Lee JS, Kang SJ and Choi BD. 2006. Seasonal variation in the nutritional content of mideodeok Styela clava. J Fish Sci Technol 9, 49-56.

National Fisheries Research Development Institute. 2008. Korea marine environment data [Internet]. National Fisheries Research Development Institute, Busan, KR, [Accessed 13 Aug 2011], http://www. nfrda.re.kr.

Nishibori K. 1958. Studies on the pigments of marine animals. VI. Carotenoids of some tunicates. Publ Seto Mar Biol Lab Kyoto Univ Jpn 7, 181-192.

Orban E, Lena GD, Nevigato T, Casini I, Marzetti A and Caproni R. 2002. Seasonal changes in meat content, condition index and chemical composition of mussels (Mytilus galloprovincialis) cultured in two different Italian sites. Food Chem 77, 57-65.

Osawa T and Namiki M. 1981. A novel type of antioxidant isolated from leaf wax of Eucalyptus leaves. Agric Biol Chem 45, 735-739.

Oyaizu M. 1986. Studies on browning reaction: antioxidative activities of browning reaction products prepared from glucose amine. Jpn J Nutr 44, 307-315.

Procházková D, Boušová I and Wilhelmová N. 2011. Antioxidant and prooxidant properties of flavonoids. Fitoterapia 82, 513-523.

Rebachuk NM, Maksimov OB, Boguslavskaya LS and Fedoreev SA. 1985. Carotenoids of the ascidian Halocynthia aurantium. Chem Nat Compd 20, 407-409.
Rice-Evans CA, Miller NJ, Bolwell PG, Bramley PM and Pridham JB. 1995. The relative antioxidant activities of plant-derived polyphenolic flavonoids. Free Radic Res 22, 375-383.

Roginsky V and Lissi EA. 2005. Review of methods to determine chainbreaking antioxidant activity in food. Food Chem 92, 235-254.

Sanina NM and Kostetsky EY. 2002. Thermotropic behavior of major phospholipids from marine invertebrates: changes with warm-acclimation and seasonal acclimatization. Comp Biochem Physiol B Biochem Mol Biol 133, 143-153.

Shim YY, Kakuda Y and Shi J. 2009. Synergistic antioxidant effects of lycopene and other antioxidants on methyl linoleate autooxidation. Food Sci Biotechnol 18, 904-909.

Shon MY, Kim TH and Sung NJ. 2003. Antioxidants and free radical scavenging activity of Phellinus baumii (Phellinus of Hymenochaetaceae) extracts. Food Chem 82, 593-597.

Siriwardhana N, Lee K-W, Kim S-H, Ha JW and Jeon Y-J. 2003. Antioxidant activity of Hizikia fusiformis on reactive oxygen species scavenging and lipid peroxidation inhibition. Food Sci Technol Int 9, 339-346.

Slinkard K and Singleton VL. 1977. Total phenol analysis: automation and comparison with manual methods. Am J Enol Vitic 28, 49-55.

Thiyagarajan V and Qian PY. 2003. Effect of temperature, salinity and delayed attachment on development of the solitary ascidian Styela plicata (Lesueur). J Exp Mar Biol Ecol 290, 133-146.

Tsuchiya Y and Suzuki Y. 1960. Biochemical studies of the ascidian, Cynthia roretzi v. Drasche IV. Carotenoids in test. Tohoku J Argic Res 10, 397-407.

Yen GC, Hung YL and Hsieh CL. 2000. Protective effect of extracts of Mesona-procumbens Hemsl. on DNA damage in human lymphocytes exposed to hydrogen peroxide and UV irradiation. Food Chem Toxicol 38, 747-754. 